\title{
FISH BOWL TEACHING TECHNIQUE FOR IIND YEAR MBBS STUDENTS IN AIMSR
}

\author{
Gandham Pavani ${ }^{1}$
}

${ }^{1}$ Associate Professor, Department of Microbiology, Apollo Institute of Medical Sciences and Research.

ABSTRACT
BACKGROUND
Many students are not attentive and active during lecture classes in a Medical College. There are a variety of ways to engage
students in the classroom that complement the lecture material by initiating, supplementing and/or reinforcing the content of the
day. One such method is Fish Bowl discussion. The present study was conducted to analyse the use of fish bowl technique of teaching
along with lecture in a medical college.

\section{MATERIALS AND METHODS}

A teacher conducted a 20-minute lecture class followed by a Fish Bowl discussion for 30 minutes. For Fish Bowl, the students in the class were divided into two groups. Group I were given a topic for discussion based on the teachers' lecture. Group II were asked to observe the Group I. Later the task given to Group I and Group II were reversed. During the discussion, the teacher guided the participants when needed and moderated the discussion. The two group discussions were followed by plenary presentation. The total time allotted for Fish Bowl was for 30 minutes. At the end of the two sessions, feedback was taken from the students about their views on Fish Bowl teaching technique.

\section{RESULTS}

Lecture with Fish Bowl discussions stimulated interest in the class in $95 \%$ of the students; $90 \%$ of the students were able to retain information better with 'Lecture with Fish Bowl' and 10\% students felt that lecture alone was better; $95 \%$ of the students were more satisfied with 'Lecture along with Fish Bowl' when compared to lecture alone. Combination of teaching methods (Lecture with Fish Bowl) was liked by $90 \%$ of our students rather than a single method of teaching (Lecture alone) which was liked by only $10 \%$ of the students.

\section{CONCLUSION}

Lecture with Fish Bowl is more effective than lecture alone. Combination of lecture and Fish Bowl is a better satisfying teaching technique for the students when compared to lecture alone.

\section{KEYWORDS}

Lecture, Fish Bowl Teaching Technique.

HOW TO CITE THIS ARTICLE: Pavani G. Fish bowl teaching technique for IInd year MBBS students in AIMSR. J. Evolution Med. Dent Sci. 2016;5(32):1713-1715, DOI: 10.14260/jemds/2016/404

\section{INTRODUCTION}

Medical education is an important factor in the progress of any country. Across the world, increasing attention is being given to the quality of teaching and learning in the Medical Colleges.[1] But many students are not attentive and active during lecture classes in a Medical College. There are many reasons for the same. Some feel that they can read from books, others are busy with electronic gadgets, some are exhausted after their clinical postings. So we need to do something for improving listening activity and active participation of students in classes in a Medical College. The "Fish Bowl" is a teaching strategy that aids in active participation of students. This is a cooperative-learning structure.[2] Spending time on this method is an investment, which will yield a more productive, efficient and engaging classroom environment.

Financial or Other, Competing Interest: None.

Submission 04-03-2016, Peer Review 31-03-2016,

Acceptance 05-04-2016, Published 20-04-2016.

Corresponding Author:

Dr. Gandham Pavani,

Associate Professor,

Department of Microbiology,

Apollo Institute of Medical Sciences and Research,

Jubilee Hills,

Hyderabad-500096.

E-mail:drpavanic@gmail.com

DOI: 10.14260/jemds/2016/404
Moreover, several research studies confirmed that such small group teaching methods should be an important component of undergraduate medical education. ${ }^{[3,4]}$ So the present study was conducted to analyse the utility of Fish Bowl technique of teaching along with lecture in a Medical College.

\section{METHODS}

This study was conducted as a part of the group discussion class in Microbiology Department of AIMSR in January 2015. Initially, a teacher conducted a 20-minute lecture class on candidiasis and cryptococcosis. Following the teachers' class, the chairs in the class were arranged in two circles, an inner circle and an outer circle; 20 students in the class were divided into two groups according to their roll numbers. The first group of 10 students [Group I] were made to sit in the inner circle, who were called fish were given a topic for discussion based on the teachers' lecture. They were instructed to hold a discussion with the representative members of their group. The students were acquainted with the rules of the fish before the Fish Bowl discussion, i.e. each speaker's idea should be stated and supported with evidence from the lecture if others in the group agree with the speaker; then they shall offer additional evidence to support the idea and if others disagree with the speaker they should offer evidence to support their point. 
The other group of another 10 students [Group II] were made to sit in the outer circle and were asked to observe the Group I and were called the fish watchers. Fish watchers were instructed to listen carefully to their fish and take notes on their fish's contribution to the discussion. Later the places of Group I and GROUP II were reversed and Group II students were given another topic based on the teachers' lecture for group discussion and Group I students were made fish watchers. During the discussion, the teacher guided the participants when needed and moderated the discussion. The two group discussions were followed by plenary presentation. One student from each group was asked to report about the active participation of the other group in discussion to the teacher in-charge. Each Fish Bowl discussion session was for a duration of 10 minutes each and plenary session was for a duration of 5 minutes. Hence, the total time allotted for Fish Bowl was 30 minutes for both sessions. At the end of the two sessions, feedback was taken from the students by means of a questionnaire about their views on Fish Bowl teaching technique, which had to be filled up in another 10 minutes.

\section{A Questionnaire was given to all the 20 Students having the following Questions:}

\begin{tabular}{|c|c|c|}
\hline $\begin{array}{c}\text { Which method } \\
\text { stimulated interest? }\end{array}$ & & \\
\hline $\begin{array}{c}\text { Which method was able } \\
\text { to retain more } \\
\text { information? }\end{array}$ & $\begin{array}{c}\text { Lecture with Fish } \\
\text { Bowl Discussion }\end{array}$ \\
\hline $\begin{array}{c}\text { Student satisfaction } \\
\text { was more with which } \\
\text { method? }\end{array}$ & & \\
\hline $\begin{array}{c}\text { Which method is } \\
\text { better? }\end{array}$ & & \\
\hline
\end{tabular}

The study was for a total duration of 60 minutes.

\section{DISCUSSION}

The common and greatest challenge faced by the teacher in a Medical College is attentiveness of students and their involvement and participation in the classes.[5] Moreover teaching learning process enforces a great deal of expectations from the teacher, equivalent participation from students and effective classroom management.[6] Moreover the tough curriculum in a Medical College need to be made interesting by the implementation of new teaching learning strategies.[7] 'Lecture with Fish Bowl discussions' inculcated interest in the class in majority (95\%) of the students. Lectures interspersed with discussions have always inculcated interest in students as seen by Baetty et al.[8] also which was in collaboration with our study. The barriers to developing interest in students can be plunged if learners are motivated to learn. The teacher in this method acts like a facilitator, launching friendly and conducive environment to develop internal motivation towards learning and thereby inculcating interest. Moreover lecture with Fish Bowl is more student-centered, while lecture alone is more teacher centered.[9]

Students need to retain information from classes for interpretation and application of information with respect to importance of the content. The instructor's job is not over till they have assisted learner in retaining the information. In our study, $90 \%$ students were able to retain information better with 'lecture with Fish Bowl' compared to only 10\% students who felt that lecture alone was better. This was also appreciated by Gibbs et al.[10] who found that interactive discussions before or after a lecture always led to retaining information better. Moreover, the retention in memory is the end-result of overall effectiveness of the lecture. In our study, retention of lecture information was more after lecture with Fish Bowl. Hence, it can be concluded that 'lecture along with Fish Bowl discussion' is more effective than lecture alone. However, $10 \%$ of our students felt that lecture alone was better because they could not follow the Fish Bowl discussion properly. Probably, this could be because of the limited time allotted to the Fish Bowl discussion, i.e. 15 minutes for each session. The time per session could be increased in the future sessions to make these sessions more effective.

In the present study, student satisfaction was more with 'Lecture along with Fish Bowl' (95\%) when compared with lecture alone. This could be because any interactive teaching technique always increases the satisfaction of both teachers and students in medical education due to active involvement, increased attention and motivation. [11] Student's satisfaction is inversely proportional to the class room size in any educational institution. This was also opined by Coles et al.[12] Fish Bowl discussions are always conducted in small groups, which therefore result in more student satisfaction.

In our study, combination of teaching methods (Lecture with Fish Bowl) was liked by majority (90\%) of our students rather than a single method of teaching (Lecture alone), which was liked by $10 \%$ of the students. Our study can be compared with the study done by Chaudhary et al.[13] In their study also majority of the students $(67.1 \%)$ favoured combination of teaching methods to single method of teaching. Combination teaching method is most satisfied teaching method, because the inherent deficiency of one method is compensated by the other.[14]

\section{CONCLUSION}

Fish Bowl method of teaching inculcated interest in majority of the students and the students were able to retain information better with 'lecture along with Fish Bowl.' The more long-lasting the retention of lecture information in memory, the more effective is the lecture. Hence, lecture with Fish Bowl is more effective than lecture alone. However, the lecture with Fish Bowl discussion can be made more effective by increasing the time for Fish Bowl discussion. Combination of lecture and Fish Bowl is a better satisfying teaching technique for the students, because the student is actively involved and more learning takes place and also the deficiencies of one method would be compensated by the other.

\section{REFERENCES}

1. Vasundhara Devi D, Kiran Deedi M. Teaching and learning methodology in medical education: an analysis in GSL medical college, Rajamundry, AP. JEMDS 2015;4(72):12557-65.

2. San San T, Nyunt Ei Ei. Collaborative learning with think pair share technique. Computer Applications: An International Journal 2015;2(1):1-11.

3. Shatzer JH. Instructional methods. Acad Med 1998;73(9):38-45. 
4. Walton H. Small group methods in medical teaching. Medical Education 1997;31(6):459-64.

5. Rehman R, Afzal K, Kamran A. Interactive lectures: a perspective of students and lecturers. J Postgrad Med Inst 2013;27(2):152-6.

6. Kamran A, Rehman R, Iqbal A. Importance of clinically oriented problem solving tutorials (COPST) in teaching of physiology. Rawal Med J 2011;36(3):233-7.

7. Vishram S, Poonam K. A paradigm shift from teaching to learning gross anatomy a metaanalysis of implications for instructional methods. Journal of Anatomical society of India 2013;62(1):84-9.

8. Ian D Beatty. Transforming student learning with classroom communication systems. Educause Center for Applied Research Bulletin 2004;3:2-13.

9. Brophy J. Synthesis of research on strategies for motivating students to learn. Educational Leadership 1987;45(2):40-8.
10. Gibbs G, Habeshaw S, Habeshaw T. Improving student learning during lectures. Medical Teacher 1987;9(1):1120.

11. Yvonne S, Linda S. Interactive lecturing: strategies for increasing participation in large group presentations. Medical Teacher 1999;21(1):37-44.

12. Coles C. Variability of student ratings of accounting teaching: evidence from a scottish business school. International Journal of Management Education 2002;2(2):30-40.

13. Chaudary R, Dullo P, Gupta U. Attitude of 1st MBBS medical students about two different visual aids in physilology lectures. Pak J Physiol 2009;5(2):16-9.

14. Priyadarshini KS, Shetty HV, Reena R. Assessment of different teaching aids and teaching methods for the better perception of biochemistry by 1st MBBS students. Journal of Evolution of Medical and Dental Sciences 2012;1(6):1159-65. 